\title{
Measurement of Anxiety in Youth
}

\author{
Dr. Indrajitsinh.D. Thakor ${ }^{1 *}$
}

\section{ABSTRACT}

The purpose of this study was to measure anxiety level in youth, who study in higher secondary school. In this research paper "Sinha's Comprehensive Anxiety Test” (SCAT) was used. The random sample $(\mathrm{N}=125)$ was taken from the school. (59 Male And 66 Female ). " $\mathrm{t}$ ” Test was calculated to find out the result. The " $t$ " value of "Sinha's Comprehensive Anxiety Test" of school students comes to 4.45 which is significant at 0.01 level. This shows that, there is significant difference between youth (Male and Female) school students On Anxiety Test. Whereas Male and Female school students differ in respect of anxiety. The detail results are indicated in the paper.

Keywords: Anxiety, Youth, Gujarat.

Dramatic changes have taken place in the society, thus anxiety has become more immediate focal point of interest. Due to advancement in the technology and atomization, the sedentary tendency has developed among the people, which is great threat to the health.

Anxiety has many facets that cannot be encompassed in any simple definition. Mostly anxiety prevails when individuals are at odds with themselves. According to Cattell and others who have sampled anxiety scores in people of various ages, anxiety levels rise during the later adolescent years and also in the sixties. Anxiety is an emotional state closely related to fear, occurs when a person worries about what might happen in future, or when he is fearful about some vague or unknown thing, which he cannot explain. We saw, the life way is not very simple for today's human being. There are lots of personal and social problems seen in life. Human being himself and herself is sad and unsatisfied. These types of mentality are in his and her mind.

Anxiety is currently a central explanatory concept in most theories of personality and psychopathology and it is widely regarded as a principal cause of such diverse behavior as insomnia, debilitating psychological and psychosomatic, immoral and sinful acts and even instances of creative self-expression. Anxiety, by contrast, arises in response to apparently

\footnotetext{
${ }^{1}$ M \& V Arts And Commerce College, Halol, Gujarat

*Responding Author

(C) 2016 I I Thakor; licensee IJIP. This is an Open Access Research distributed under the terms of the Creative Commons Attribution License (http://creativecommons.org/licenses/by/2.0), which permits unrestricted use, distribution, and reproduction in any Medium, provided the original work is properly cited.
} 
innocuous situation or is the product of subjective, internal emotional conflicts the causes of which may not be apparent to the person himself. Some anxiety inevitably arises in the course of daily life and is normal.

There are many causes for anxiety. Sigmund Freud viewed anxiety as the symptomatic expression of the inner emotional conflict caused when a person suppresses from conscious awareness experiences, feelings, or impulses that are too threatening or disturbing to live with. Anxiety is also viewed as arising from threats to an individual's ego or self-esteem, as in the case of inadequate sexual or job performance. Behavioral psychologists view anxiety as an unfortunate learned response to frightening events in real life.

According to Rubebush (1963), Females have been found to have higher score of anxiety than Males. Costello et al; (2003), found that adolescent Females report a greater number of worries, more separation anxiety and higher levels of generalized anxiety. Ojha (2005), conducted a study and revealed that $25 \%$ Males have extremely high anxiety whereas only 6.7 Females have high academic anxiety. Robichaud et al; (2003), found that Female reported more worry that Male. Female out number Male in each illness except for OCD, in which both sexes have an equal likelihood of being affected.

\section{OBJECTIVES OF STUDY}

(i) To measure a Male Anxiety.

(ii) To measure a Female Anxiety.

\section{METHODOLOGY}

\section{Sample:}

The sample of the present study consisted of 59 male and 66female (Total sample: 125). They are randomly selected from different schools of Ghogamba city.

\section{Tool:}

Comprehensive Anxiety Test, Constructed and Standardized by Sinha, A. K. P. and Sinha L. N. K.(1971), To measure the Anxiety of school and college students. Test Re-Test reliability is shown 0.85 and Spearman Brown formula are 0.92. The validity of test is 0.62 .The scale consists of 90 items. The maximum possible score of this test is 90 and minimum possible scores is zero. Each item of the test is scored 01(one) for positive response and 00(zero) for negative response. The sum of all positive or yes responses would be the total anxiety score of the individual.

\section{Hypotheses:}

There is no significant difference between the mean scores of male and female of anxiety. 


\section{Procedure:}

The data collected in small groups in the classroom situation. During the testing session respondents were instructed in brief about the purpose of investigation. They were instructed to read the items carefully and to put a tick mark in one of the provided spaces according to their opinion "YES" or "NO" and then after all the forms put on transparency (Scoring Key) one by one and calculate row scores of all forms and find out MEAN, SD and " $t$ " - Value of respondents.

\section{RESULTS}

The finding of the study on problem of Measurement between the youth of Anxiety of school students. Results are given bellow.

\section{Table, Anxiety Of High School Students}

\begin{tabular}{|l|l|l|l|l|l|l|l|}
\hline Sr. No & Gender & N & Mean & SD & df & $\begin{array}{l}\text { t ” ”lue } \\
\text { Value }\end{array}$ & Sig. Level \\
\hline 01 & Male & 59 & 23.12 & 13.88 & \multirow{2}{*}{123} & 4.45 & 0.01 \\
\hline 02 & Female & 66 & 34.48 & 14.56 & & & \\
\hline
\end{tabular}

Table Value. $=2.32 \quad$ Calculated $t=4.45 \quad$ Level of Significant. $=0.01$

\section{DISCUSSION}

According to the table, the mean scores of Anxiety between youth (Male and Female) of schools students are 23.12 and 34.48 respectively. Indicating that there is a difference in Anxiety between youth. The results show that Female students have more Anxiety (34.48) than Male students (23.12). The " $t$ " value difference between youth (Male and Female) of schools students is 4.45 , which is significant at 0.01 level. The table value is 2.32 at $123 \mathrm{df}$. Therefore the null hypothesis is rejected. Therefore it can be said that there is significant difference between mean scores of Anxiety of youth (Male and Female) schools students.

The, " $t$ " - Value of 4.45 is significant at 0.01 level of significance. It means that there is significant difference between youth (Male and Female) on Anxiety; hence the formulated hypothesis is that there is no significant difference between the mean scores of youth (Male and Female) on Anxiety is rejected. The difference between two mean scores was significant. So it was concluded that there was significant difference between youth (Male and Female) of schools students on Anxiety.

\section{CONCLUSIONS}

In the present study there is significant difference between youth (Male and Female) of school students on Anxiety. It shows that youth (Male and Female) play significant role so far as Anxiety is concerned. 


\section{REFERENCE}

Garrett, H. E. (1958). Statistics in Psychology and Education, ( $5^{\text {th }}$ Ed.).

Longmans, Green and Co., New York.

Poulton, R.,Milne, B. J., Craske, M. G. \&Menzies, R. G. (2001), A longitudinal study of the etiology of separation anxiety. Behaviour Research and Therapy, 39 (12), 1395-1410.

Robichaud, M, Dugas, MJ, Conway M. (2003), Gender difference in worry and associated cognitive behavioural variable. J Anxiety Disord; 17, 501-16.

Sinha, A. K. P. \&Sinha, L. N. K. (1973), Comprehensive Anxiety Test. National Psychological Corporation 4/230, KacheriGhat, Agra, 282004. 